\title{
On Some Comparison of Computing Indefinite Integrals with the Solution of the Initial-value Problem for ODE
}

\author{
MEHRİBAN İMANOVA \\ Computational mathematics, Baku State University \\ Institute of Control Systems, \\ Executive Director, Science Development Foundation \\ under the President of the Republic of Azerbaijan \\ Baku, AZERBAIJAN
}

\begin{abstract}
The initial-value problem for the ODE is one of the classical mathematical problems, which was fundamentally investigated by many authors. This problem has been basically studied by using the quadrature formulas. Note that in the construction of quadrature formulas are used interpolation polynomials with different properties. Here, has been established some connection between the ODE and definite integrals, by using of which have constructed effective methods for computing of definite integrals. By using some multistep methods have demonstrated the advantage of the multistep methods. And also demonstrated the advantages of the proposed here methods in the construction of which didn't use the theory of interpolation polynomials. Quadrature methods are studied as the special case of the multistep methods. And also have determined the maximal order of the quadrature method. Here received the apriori estimation for the errors of quadrature methods. Proposed concrete methods some of which have applied to the computing of the model definite integral.
\end{abstract}

Key-Words: - The initial-value problem, integral equation, quadrature formula, ODE, finite-difference methods.

Received: December 26, 2019. Revised: April 30, 2020. Accepted: May 13, 2020. Published: May 27, 2020.

\section{Introduction}

One of the popular methods in studying of scientific and engineering problems is the quadrature methods which is directly related with the application of definite integrals. As is known many authors in solving of the initial-value problem for ODE have used the quadrature formula. For this aim, let us consider the following problem:

$$
y^{\prime}=f(x, y), y\left(x_{0}\right)=y_{0}, \quad x_{0} \leq x \leq X .
$$

This is an initial-value problem for the ODE of the first order, which can be written as the integral equation in the following form:

$$
y(x)=y\left(x_{0}\right)+\int_{x_{0}}^{x} f(s, y(s)) d s, \quad x_{0} \leq x \leq X .
$$

Suppose that the continupus on the totality of arguments function $f(x, y)$ is defined on the domain $D=\left\{x_{0} \leq x \leq X, y \leq C\right\}$ and has the partial derivatives up to $p$, inclusively. It follows that the problem (1) has the unique solution defined on the segment $\left[x_{0}, X\right]$. As is known the problem (1) has been investigated by many authors (see [1], [2, p. 292-293], [3], [4, p. 83-109], [5]-[10]). Constructed one-step and multistep methods for solving of the problem (1). Taking into account the equivalency of the problem (1) and the integral equation (2) have been constructed the methods for solving of problem (2). To construct the methods with the higher order of accuracy, here proposed to use the finite-difference methods. And now let us consider the application of the quadrature formula to solving of the problem (1).

\section{Investigation of quadrature formula by using the numerical solution of the problem (1)}

The investigation of numerical solutions of the problem (1) by using the quadrature methods has been studied by scientists a very long time. But here proposed to investigate the quadrature methods by the help of methods using in solving of the problem (1). For the application of the quadrature formula to solve the equation (2) let us consider the following indefinite integral:

$$
y(x)=\int_{x_{0}}^{x} F(s) d s, \quad x_{0} \leq x \leq X .
$$

Suppose that sufficiently smooth function $F(x)$ is defined on the segment $\left[x_{0} X\right]$. To compute the 
integral participated in (3) one can be used the following quadrature formula:

$$
\int_{x_{0}}^{x_{l}} F(s) d s=h \sum_{i=0}^{l} \beta_{i} F\left(x_{i}\right),
$$

here the node $x_{i}(i=0,1, \ldots, n)$ are defined by the equality $x_{i}=x_{0}+i h(i=0,1, \ldots, n)$. The positive $h$ is the step-size. If here supposed that $n=k l$, then for the calculation of the value $y(x)$ must be used the composite quadrature formula which is constructed by using the following equality:

$$
\begin{gathered}
\int_{a}^{b} F(s) d s=\int_{a}^{x_{1}} F(s) d s+ \\
+\int_{x_{l}}^{x_{21}} F(s) d s+\ldots+\int_{(k-1) x_{l}}^{b} F(s) d s \quad\left(a=x_{0} ; b=x_{n}\right) .
\end{gathered}
$$

Quadrature formula, in this case, can be written as follows:

$$
y(b)=\int_{x_{0}}^{x_{n}} F(s) d s=h \sum_{j=0}^{k-1} \sum_{i=0}^{l} \beta_{i} F\left(x_{j l+i}\right) .
$$

It is known that if apply the finite-difference method to solve the problem (1), then receive:

$$
\sum_{i=0}^{l} \alpha_{i} y_{m+i}=h \sum_{i=0}^{l} \beta_{i} f_{m+i} \quad(m=0,1, \ldots, n-l),(6)
$$

here $y_{n}$ is the approximate value for the function $y(x)$ at the mesh point $x_{n}(n \geq 0)$. If put $x=x_{l}$ in the equality (3), then receive $y\left(x_{l}\right)-y_{0}=\int_{x}^{x_{l}} F(s) d s$, so as $y_{0}=0$ In this case, from the equality (4) receive that:

$$
y_{l}=y_{0}+h \sum_{i=0}^{l} \beta_{i} F\left(x_{i}\right) .
$$

It is not difficult to prove that this equality in general form can be written as following:

$$
y_{m l}=y_{(m-1) l}+h \sum_{i=0}^{l} \beta_{i} F\left(x_{(m-1) l+i}\right) .
$$

If take into account the equality $y^{\prime}(x)=F(x)$ in the equality (7), then receive non-homogeneous finite-difference equation with constant coefficients. It is known that the solution of the equation (7) can be written as the $y_{m}=\bar{y}_{m}+y_{m}^{*}$. Here $\bar{y}_{m}$-the general solution of homogeneous and $y_{m}^{*}$ is the partial solution of non-homogeneous equation. It is evident that in the case $h \rightarrow 0$ receive that $y_{m}^{*} \rightarrow 0$. Therefore the properties of the solution of equation
(7) depends from the solution of $\bar{y}_{m}$. As is known the general solution of the homogeneous equation can be written in the following form (see for example [11, p. 311-319]):

$$
y_{m}=C_{1} \lambda_{1}^{m}+C_{2} \lambda_{2}^{m}+\ldots+C_{l} \lambda_{l}^{m} .
$$

Here $\lambda_{i}(i=1,2, \ldots, l)$ are the roots of the following equation:

$$
\lambda^{l}-1=0 .
$$

All roots of this equation differ from each other and satisfy the condition $\left|\lambda_{i}\right|=1 \quad(i=1,2, \ldots, l)$. These roots in general form can be written as the following:

$\lambda_{i}=\rho(\cos \omega \alpha+i \sin \omega \alpha) \quad(i=1,2, \ldots, l)$,

here $\rho$ is the module of the roots $\lambda_{i}(i=1,2, \ldots, l)$.

And now let us consider the determination of the behavior of the solution of the non-homogeneous finite-difference equation (6). It is clear, that the properties of the equation (6) depend on the properties of the general solution of the corresponding homogeneous equation which has been investigated by many authors (see [12], [13, p. 82-89], [14, p. 205-226], [15, p. 379-394],[16]).And have been proved that if the method (6) is stable then the solution of the corresponding nonhomogeneous equation will be bounded. For the comparison of the solution of the finite-difference equation (6) and (7), let us remember the definition of the conception of stability which can be given as the following:

Definition 1. The method (6) is stable if all roots of the following polynomial:

$$
\rho(\lambda)=\alpha_{k} \lambda^{l}+\alpha_{k-1} \lambda^{l-1}+\ldots+\alpha_{1} \lambda+\alpha_{0}
$$

lie in the unit circle on the boundary of which there are no multiply root (see [3]-[7])

Note that the method (4) and its generalization method (5) satisfy the condition of stability. But in the class of method (6) there are some stable methods which are not include in the class of methods of the type (5). Among of them there are methods which have higher degrees than the method of the type (4). The next section is dedicated to prove this expression.

\section{The determination of the maximal order of accuracy for the method (7)}

To define the maximal value of order of accuracy let us consider the following conception of the degree. Definition 2. The integer value $p$ is called as the order for the method (7), if the following is hold: 


$$
\begin{gathered}
y(x+l h)-y(x)- \\
-h \sum_{i=0}^{l} \beta_{i} y^{\prime}(x+i h)=O\left(h^{p+1}\right), h \rightarrow 0 .
\end{gathered}
$$

By choosing of the coefficients of $\beta_{i}(i=0,1, \ldots, l)$ one can be define the maximal value for the degree $p$. For this aim, let us use the following Taylor series:

$$
\begin{gathered}
y(x+l h)=y(x)+l h y^{\prime}(x)+ \\
+\frac{(l h)^{2}}{2 !} y^{\prime \prime}(x)+\ldots+\frac{(l h)^{p}}{p !} y^{(p)}(x)+O\left(h^{p+1}\right), \\
y^{\prime}(x+i h)=y^{\prime}(x)+i h y^{\prime \prime}(x)+ \\
+\frac{(i h)^{2}}{2 !} y^{\prime \prime \prime}(x)+\ldots+\frac{(i h)^{p-1}}{(p-1) !} y^{(p)}(x)+O\left(h^{p+1}\right) .
\end{gathered}
$$

By taking into account the equalities (9) in the asymptotic equality (8), receive:

$$
\begin{aligned}
h y^{\prime}(x)\left(l-\sum_{i=0}^{l} \beta_{i}\right)+h^{2} y^{\prime \prime}(x)\left(\frac{l^{2}}{2 !}-\sum_{i=0}^{l} i \beta_{i}\right)+ \\
+\ldots+h^{p} y^{(p)}(x)\left(\frac{l^{p}}{p !}-\sum_{i=0}^{l} \frac{i^{p-1}}{(p-1) !} \beta_{i}\right)=O\left(h^{p+1}\right), \\
h \rightarrow 0 .
\end{aligned}
$$

As is known the system $1, x, x^{2}, \ldots, x^{p}$ (or the system $\left.y^{\prime}(x), y^{\prime \prime}(x), \ldots, y^{(p)}(x) \quad\left(y^{(j)}(x) \neq 0 ; i=0,1, \ldots, p\right)\right)$

is independed. Therefore from the equality (10) receive, that the following must be hold:

$$
\begin{gathered}
\sum_{i=0}^{l} \beta_{i}=l ; \quad \sum_{i=0}^{l} i \beta_{i}=\frac{l^{2}}{2 !} ; \ldots \\
\sum_{i=0}^{l} \frac{i^{p-1}}{(p-1) !} \beta_{i}=\frac{l^{p}}{p !} .
\end{gathered}
$$

Thus, to define the values of the degree $p$ receive non-homogeneous system of algebraic equations. Amount of the equations equals to $p$, but amount of unknowns equals to $k+1$. It is not difficult to prove that the system (11) has the unique solution for the case $p=l+1$ and has the solution which is more than 1 (one), in the case $p \leq l$. And by Dahlquist's result receive that if the method (6) is stable then there are stable methods with the degree $p_{\max }=2[l / 2]+2$ for the each value of $l$. The method (7) is more simple than the method (6). For the investigation of the method (7) let us write that in the following form:

$$
y_{n+l}=y_{n}+h \sum_{i=0}^{l} \beta_{i} y_{n+i}^{\prime} .
$$

This presentation of the method (7) is the same with the presentation of the method (6). Let us apply this method to solving of the following problem:

$$
y^{\prime}(x)=\lambda y(x), \quad y(0)=1, \quad 0 \leq x \leq X .
$$

In this case, receive the next finite-difference equation:

$$
\begin{gathered}
\left(1-h \beta_{l} t\right) y_{n+l}-h t\left(\beta_{l-1} y_{n+l-1}+\ldots+\beta_{1} y_{n+1}\right)- \\
-\left(1+h t \beta_{0}\right) y_{n}=0
\end{gathered}
$$

If $\lambda=0$ then receive that

$$
y_{n+l}-y_{n}=0,
$$

the solution for which can be written as:

$$
y_{m}=C_{1} \lambda_{1}^{m}+C_{2} \lambda_{2}^{m}+\ldots+C_{l} \lambda_{l}^{m},
$$

$\lambda_{j}(j=1,2, \ldots, l)$ are the roots of the polynomial $\rho(\lambda)=\lambda^{l}-1$. Note that all roots are distinct. In this case, the roots $\lambda_{j}^{m}(j=0,1, . ., l-1)$ can be defined in the following form:

$$
\begin{gathered}
\lambda_{j}^{m}=r^{m}\left(\cos \frac{2 j m \pi}{l+1}+i \sin \frac{2 j m \pi}{l+1}\right), \\
r=\sqrt{\cos ^{2} \frac{2 j \pi}{l+1}+\sin ^{2} \frac{2 j \pi}{l+1}} .
\end{gathered}
$$

From here receive that the module of these roots equal to one, that is $\left|\lambda_{j}\right|=1(j=1,2, \ldots, l)$, so as $r=1$. The coefficients $C_{i}(j=1,2, \ldots, l)$ can be defined by the help of the initial-value $y_{j}(j=0,1, \ldots, l-1)$. If the initial-values are bounded, that is $\left|y_{j}\right| \leq M \quad(j=0,1, \ldots, l-1)$, then receive that the solution of (15) is also bounded. Note that in this case when $\lambda_{i}$ is complex, then receive that $\lambda_{i+1}$ is also complex and is conjugate to complex value $\lambda_{i}$. Therefore the corresponding constants $C_{i}$ and $C_{i+1}$ will also self-conjugate complex numbers. It is not difficult to prove that, if $C_{i}=a_{i}+i b_{i}$, then $C_{i+1}=a_{i+1}-i b_{i+1}$. In this case, receive that:

$$
\begin{gathered}
C_{l} \lambda_{l}^{m}+C_{l+1} \lambda_{l+1}^{m}=\left(a_{i} \cos m s+a_{i+1} \sin m s\right) r^{m}, \\
\left(\lambda_{i}=r(\cos t+i \sin t)\right) .
\end{gathered}
$$

It follows that $C_{l} \lambda_{l}^{m}+C_{l+1} \lambda_{l+1}^{m}$ is bounded, it is to say that $\left|C_{l} \lambda_{l}^{m}+C_{l+1} \lambda_{l+1}^{m}\right| \leq C$, so that $r=1$.

It is evident that the equation (14) for fixed step-size $h$ will be finite-difference equation with constant coefficients. Therefore the solution of the equation (14) which is denoted by $\bar{y}_{m}$ can be presented as the following form: 


$$
\bar{y}_{m}=\bar{C}_{l} \lambda_{l}^{m}+\bar{C}_{2} \lambda_{2}^{m}+\ldots+\bar{C}_{l} \lambda_{l}^{m} .
$$

here $\lambda_{1}$ - are the roots of the polynomial:

$$
\begin{gathered}
\lambda^{l}-\frac{h t}{\left(1-h t \beta_{l}\right)}\left(\beta_{l-1} \lambda^{l-1}+\ldots+\beta_{1} \lambda\right)- \\
-\frac{1+h t \beta_{0}}{\left(1-h t \beta_{l}\right)}=0 .
\end{gathered}
$$

Let us consider the following series:

$$
\begin{gathered}
\left(1+h t \beta_{0}\right) /\left(1-h t \beta_{l}\right)= \\
=1+h t \beta_{l}+(h t)^{2} \beta_{l}\left(\beta_{l}+\beta_{0}\right)+(h t)^{3} \beta^{2}{ }_{l}\left(\beta_{l}+\beta_{0}\right)+\ldots
\end{gathered}
$$

As is known if the method (12) has the degree $p>k$ then the coefficient $\beta_{l}$ satisfies to the condition as $\beta_{l}>0$.In this case the constant term in the expression (16) can be written as (17). And now let us presuppose that the size $l$ is even. Then receive that one of the roots of the polynomial $\rho(\lambda)=\lambda^{l}-1$ equal to -1 (minus one). For the investigation of this case let us put $l=2$. If in this case take $t<0$, then receive that one of the roots of the equation (16) can be presented as:

$$
\lambda_{2}(h)=-1-t h-\frac{(t h)^{2}}{2}+\ldots \approx-\exp (-t h+O(t h)) .
$$

From here receive that

$$
C_{2} \lambda_{2}^{m}=C_{2}(-1)^{m} \exp (m t h+O(t h))
$$

(see [4, p. 379-384]). And in this case other root can be defined by the formula:

$\lambda_{1}(h)=-1-t h+\frac{(t h)^{2}}{2}+\ldots \approx-\exp (-t h(1+O(h)))$.

From here receive that $\left(\lambda_{1}(h)\right)^{m}=\exp (-m t h+O(h))$ which corresponds to the exact solution of the problem (13). If the size of $l$ is odd in this case one of roots for the polynomial $\rho(\lambda)$ will equal to one $\left(\lambda_{1}=1\right)$ and the others will be complex numbers, the module for which equals to 1 (one). Thus receive that method (12) is stable and has the degree $p \leq l+1$. It follows that the method (12) is convergent. It is known that if the method is convergent then its coefficients must to satisfy the following conditions (see [5],[6]):

A. The coefficients $\beta_{i} \quad(i=0,1, \ldots, l)$ are some real numbers.

B. The roots of the polynomial $\sigma(\lambda)=\sum_{i=0}^{l} \beta_{i} \lambda^{i}$ are differ from the roots of polynomial $\rho(\lambda)=\lambda^{l}-1$.
C. $\sigma(1) \neq 0$ and $p \geq 1$. It follows from the condition $\mathrm{B}$, that the conditions $\sigma(1) \neq 0$ will be satisfied always.

And verification of the necessity of conditions of convergence for the method (12) is very easy. Because $\rho(1)=1^{l}-1=0$.

Suppose that coefficients of the method (12) satisfies to the conditions A, B and C. Then the rate of convergence of the method (12) can be established by the following theorem:

Theorem. Let the method has the degree $p$. Then the following estimation for its errors will be hold:

$$
\begin{array}{r}
\left|y(x)-y_{m}\right| \leq C\left(\max _{0 \leq i<l}\left|y\left(x_{i}\right)-y_{i}\right|+M_{1}\right) h^{p}, \\
h \rightarrow 0,
\end{array}
$$

here $x=x_{0}+m h$-fixed point.

The similar theorems have been proved by some authors (see [4, p. 385], [5],[6]). By the investigation of the linear system of algebraic equations (11), receive that in the class of methods of the type (12) there are methods with the degree $p=l+2$ for the even $l$. For example, in the case $l=2$, from the method (12) it follows the Simpson method. Thus receive that in the class of methods (12) there are exist methods with the degree $p=l+1$ if $l$ is odd and exist methods with the degree $p=l+2$ if $l$ is even.

For the illustration of the received here results let us consider the application of the methods of the type (12) to computation of some definite integrals.

\section{Application of some concrete methods to computing of the model of definite integral}

Let us note that the maximal degree for the method (6) equals to $2 l$. But the method (12) always has the degree $p=2[l / 2]+2$ and if $p=l+2$, then $\lambda= \pm 1$ will roots for the characteristic polynomial of the method (12). It follows note that the region of the stability for the stable methods of the type (6) are wide than the region of stability for the method of type (12). For example, the boundary of the region of stability for the Simpson method equals to zero. But in the class of methods (6) there are methods which are freed from this disadvantage. It is known that in solving many scientific and engineering problems arise necessity to construct more exact methods for calculation of definite integrals. 
For this aim, one can be used the Lableotto, Chebyshev, Gauss and etc. methods. Note that the coefficients of these methods are fixed. Note that the coefficients of these methods are fixed. Therefore it is impossible to construct the methods of above-mentioned type with the new properties by choosing the coefficients. However by using the methods of the type (6) one can be constructed methods with new properties by choosing some coefficients. For example, to calculate the definite integrals by using the problem (1) one can be used the following multistep hybrid method:

$$
\begin{array}{r}
\sum_{i=0}^{l} \alpha_{i} y_{n+i}=h \sum_{i=0}^{l} \beta_{i} f_{n+i}+h \sum_{i=0}^{l} \gamma_{i} f_{n+i+v_{i}} \\
\left(\left|v_{i}\right|<1 ; i=0,1, \ldots, l\right),
\end{array}
$$

Let us note that in the class of methods of the type (19) there are stable methods with the degree $p=3 k+3$. One can be received the Gauss method from the (19) in the case $\beta_{i}=0(i=0,1, \ldots, l)$. It follows from here that the method (19) is more general than the multistep methods with constant coefficients or the Gauss methods. These methods were call as hybrid methods and have investigated by authors (see for example [7]-[10], [17]-[24]).

And now let us consider the computation of the following definite integral:

$$
I d=\lambda \int_{0}^{1} \exp (\lambda s) d s
$$

the exact value for which equals to $\exp (\lambda)-1$.

For computing of the values of above given integral let us use the following methods having the different properties:

$$
\begin{gathered}
y_{i+3}=\left(y_{i+2}+y_{i+1}+y_{i}\right) / 3+ \\
+h\left(13 y_{i+3}^{\prime}+39 y_{i+2}^{\prime}+15 y_{i+1}^{\prime}+5 y_{i}^{\prime}\right) / 36, \\
y_{i+3}=y_{i+2}+h\left(9 y_{i+3}^{\prime}+19 y_{i+2}^{\prime}-5 y_{i+1}^{\prime}+y_{i}^{\prime}\right) / 24, \\
y_{i+3}=y_{i+1}+h\left(y_{i+3}^{\prime}+4 y_{i+2}^{\prime}+y_{i+1}^{\prime}\right) / 3, \\
y_{i+3}=y_{i}+3 h\left(y_{i+3}^{\prime}+3 y_{i+2}^{\prime}+3 y_{i+1}^{\prime}+y_{i}^{\prime}\right) / 8 .
\end{gathered}
$$

All methods are stable and have the degree $p=4$. Let us compare these methods. The methods (22) and (23) are quadrature formulas, but methods (20) and (21) aren't include in the class of quadrature formulas. All methods can be applied to solving of the problem (1). In the construction of Simpson method (formula (22)) has used three node points but in the construction of other methods have used four node points. If solve non-homogeneous finitedifference equations (20)-(23), then receive:

$y_{m}=C_{1}+\left(\bar{a}_{i} \cos (m s)+\bar{a}_{i+1} \sin (m s)\right) 3^{-m}+\phi_{1}(h)$ for the method (20),

$y_{m}=C_{1}+\phi_{2}(h)$ for the method (21),

$y_{m}=C_{1}+(-1)^{m} C_{2}+\phi_{3}(h)$ for the method (22),

$y_{m}=C_{1}+\left(a_{i} \cos (m s)+a_{i+1} \sin (m s)\right)+\phi_{4}(h)$ for

the method (23).

The functions $\phi_{j}(h)(j=1,2,3,4)$ are the partial solution for the corresponding non-homogeneous equations. By the comparison of the linear part of proposed method one can say that the method (21) is better than others. By solving of model problem of type (1) will show that in reality this conclusion can be incorrect. In order to give more wide information about increasing of errors for each above-described methods here by decided tabulated the results receiving in solving of initial-value problem for indefinite integral corresponding to example. And also here decided to apply one of simple hybrid methods for solving of this problem. For the comparison of the results receiving in the computation of given example it is sufficient to take into account the last value tabulated in the presented tables.

Let us note that the hybrid methods are more exact than the methods of type (6). For the demonstration of advantages of hybrid methods let us apply the following hybrid method to compute the given example which has the degree $p=4$ :

$y_{i+1}=y_{i}+h\left(y_{i+1 / 2-\sqrt{3} / 6}^{\prime}+y_{i+1 / 2+\sqrt{3} / 6}^{\prime}\right)$.

The results are tabulated in the following tables:

Table 1. The errors of the methods (20) with $m=1, h=0,1$

\begin{tabular}{|c|l|l|l|l|l|}
\hline$X_{i}$ & $\begin{array}{l}\text { The } \\
\text { errors of } \\
\text { the } \\
\text { methods } \\
(20)\end{array}$ & $\begin{array}{l}\text { The } \\
\text { errors of } \\
\text { the } \\
\text { methods } \\
(21)\end{array}$ & $\begin{array}{l}\text { The } \\
\text { errors of } \\
\text { the } \\
\text { methods } \\
(22)\end{array}$ & $\begin{array}{l}\text { The } \\
\text { errors of } \\
\text { the } \\
\text { methods } \\
(23)\end{array}$ & $\begin{array}{l}\text { The errors of } \\
\text { the methods } \\
(24)\end{array}$ \\
\hline 0.3 & $2.95 \mathrm{E}-7$ & $3.13 \mathrm{E}-7$ & $1.35 \mathrm{E}-7$ & $4.36 \mathrm{E}-7$ & $2.97 \mathrm{E}-9$ \\
\hline 0.7 & $1.06 \mathrm{E}-6$ & $1.93 \mathrm{E}-6$ & $5.04 \mathrm{E}-7$ & $1.13 \mathrm{E}-6$ & $1.83 \mathrm{E}-8$ \\
\hline 1.1 & $2.27 \mathrm{E}-6$ & $4.34 \mathrm{E}-6$ & $1.05 \mathrm{E}-6$ & $2.22 \mathrm{E}-6$ & $4.12 \mathrm{E}-8$ \\
\hline 1.5 & $4.08 \mathrm{E}-6$ & $7.95 \mathrm{E}-6$ & $1.87 \mathrm{E}-6$ & $4.34 \mathrm{E}-6$ & $7.54 \mathrm{E}-8$ \\
\hline 2.0 & $7.64 \mathrm{E}-6$ & $1.50 \mathrm{E}-5$ & $3.42 \mathrm{E}-6$ & $7.69 \mathrm{E}-6$ & $1.42 \mathrm{E}-7$ \\
\hline
\end{tabular}

Table 2. The errors of the methods (20) with $m=-1, h=0,1$ 


\begin{tabular}{|c|c|c|c|c|c|}
\hline$X_{i}$ & $\begin{array}{c}\text { The } \\
\text { errors of } \\
\text { the } \\
\text { methods } \\
(20)\end{array}$ & $\begin{array}{c}\text { The } \\
\text { errors of } \\
\text { the } \\
\text { methods } \\
(21)\end{array}$ & $\begin{array}{c}\text { The } \\
\text { errors of } \\
\text { the } \\
\text { methods } \\
(22)\end{array}$ & $\begin{array}{c}\text { The } \\
\text { errors of } \\
\text { the } \\
\text { methods } \\
(23)\end{array}$ & $\begin{array}{c}\text { The errors } \\
\text { of the } \\
\text { methods } \\
(24)\end{array}$ \\
\hline 0.3 & $2.12 \mathrm{E}-7$ & $2.22 \mathrm{E}-7$ & $9.10 \mathrm{E}-8$ & $3.23 \mathrm{E}-7$ & $1.80 \mathrm{E}-9$ \\
\hline 0.7 & $4.82 \mathrm{E}-7$ & $9.20 \mathrm{E}-7$ & $2.26 \mathrm{E}-7$ & $5.09 \mathrm{E}-7$ & $7.45 \mathrm{E}-9$ \\
\hline 1.1 & $6.92 \mathrm{E}-7$ & $1.38 \mathrm{E}-6$ & $3.17 \mathrm{E}-7$ & $6.05 \mathrm{E}-7$ & $1.12 \mathrm{E}-8$ \\
\hline 1.5 & $8.31 \mathrm{E}-7$ & $1.70 \mathrm{E}-6$ & $3.78 \mathrm{E}-7$ & $9.68 \mathrm{E}-7$ & $1.37 \mathrm{E}-8$ \\
\hline 2.0 & $9.43 \mathrm{E}-7$ & $1.95 \mathrm{E}-6$ & $3.79 \mathrm{E}-7$ & $8.52 \mathrm{E}-7$ & $1.58 \mathrm{E}-8$ \\
\hline
\end{tabular}

Ta

ble 3. The errors of the methods (20) with $m=1, h=0,01$

\begin{tabular}{|c|l|l|l|l|l|}
\hline$X_{i}$ & $\begin{array}{l}\text { The } \\
\text { errors of } \\
\text { the } \\
\text { methods } \\
(20)\end{array}$ & $\begin{array}{l}\text { The } \\
\text { errors of } \\
\text { the } \\
\text { methods } \\
(21)\end{array}$ & $\begin{array}{l}\text { The } \\
\text { errors of } \\
\text { the } \\
\text { methods } \\
(22)\end{array}$ & $\begin{array}{l}\text { The } \\
\text { errors of } \\
\text { the } \\
\text { methods } \\
(23)\end{array}$ & $\begin{array}{l}\text { The errors of } \\
\text { the methods } \\
(24)\end{array}$ \\
\hline 0.3 & $4.19 \mathrm{E}-11$ & $8.63 \mathrm{E}-11$ & $1.83 \mathrm{E}-11$ & $4.37 \mathrm{E}-11$ & $7.62 \mathrm{E}-13$ \\
\hline 0.7 & $1.24 \mathrm{E}-10$ & $2.60 \mathrm{E}-10$ & $5.51 \mathrm{E}-11$ & $1.25 \mathrm{E}-10$ & $2.30 \mathrm{E}-12$ \\
\hline 1.1 & $2.48 \mathrm{E}-10$ & $5.19 \mathrm{E}-10$ & $1.10 \mathrm{E}-10$ & $2.47 \mathrm{E}-10$ & $4.59 \mathrm{E}-12$ \\
\hline 1.5 & $4.32 \mathrm{E}-10$ & $9.06 \mathrm{E}-10$ & $1.92 \mathrm{E}-10$ & $4.35 \mathrm{E}-10$ & $8.01 \mathrm{E}-12$ \\
\hline 2.0 & $7.95 \mathrm{E}-10$ & $1.66 \mathrm{E}-9$ & $3.53 \mathrm{E}-10$ & $7.96 \mathrm{E}-10$ & $1.47 \mathrm{E}-11$ \\
\hline
\end{tabular}

Table 4. The errors of the methods (20) with $m=-1, h=0,01$

\begin{tabular}{|c|l|l|l|l|l|}
\hline$X_{i}$ & $\begin{array}{l}\text { The } \\
\text { errors of } \\
\text { the } \\
\text { methods } \\
(20)\end{array}$ & $\begin{array}{l}\text { The } \\
\text { errors of } \\
\text { the } \\
\text { methods } \\
(21)\end{array}$ & $\begin{array}{l}\text { The } \\
\text { errors of } \\
\text { the } \\
\text { methods } \\
(22)\end{array}$ & $\begin{array}{l}\text { The } \\
\text { errors of } \\
\text { the } \\
\text { methods } \\
(23)\end{array}$ & $\begin{array}{l}\text { The errors of } \\
\text { the methods } \\
(24)\end{array}$ \\
\hline 0.3 & $3.08 \mathrm{E}-11$ & $6.36 \mathrm{E}-11$ & $1.32 \mathrm{E}-11$ & $3.23 \mathrm{E}-11$ & $5.54 \mathrm{E}-13$ \\
\hline 0.7 & $6.13 \mathrm{E}-11$ & $1.28 \mathrm{E}-10$ & $2.68 \mathrm{E}-11$ & $6.16 \mathrm{E}-11$ & $1.11 \mathrm{E}-12$ \\
\hline 1.1 & $8.18 \mathrm{E}-11$ & $1.72 \mathrm{E}-10$ & $3.59 \mathrm{E}-11$ & $8.09 \mathrm{E}-11$ & $1.49 \mathrm{E}-12$ \\
\hline 1.5 & $9.56 \mathrm{E}-11$ & $2.01 \mathrm{E}-10$ & $4.20 \mathrm{E}-11$ & $9.71 \mathrm{E}-11$ & $1.75 \mathrm{E}-12$ \\
\hline 2.0 & $1.06 \mathrm{E}-10$ & $2.24 \mathrm{E}-10$ & $4.69 \mathrm{E}-11$ & $1.05 \mathrm{E}-10$ & $1.95 \mathrm{E}-12$ \\
\hline
\end{tabular}

Table 5. The errors of the methods (20) with $m=-10, h=0,1$

\begin{tabular}{|c|l|l|l|l|l|}
\hline$X_{i}$ & $\begin{array}{l}\text { The } \\
\text { errors of } \\
\text { the } \\
\text { methods } \\
(20)\end{array}$ & $\begin{array}{l}\text { The } \\
\text { errors of } \\
\text { the } \\
\text { methods } \\
(21)\end{array}$ & $\begin{array}{l}\text { The } \\
\text { errors of } \\
\text { the } \\
\text { methods } \\
(22)\end{array}$ & $\begin{array}{l}\text { The } \\
\text { errors of } \\
\text { the } \\
\text { methods } \\
(23)\end{array}$ & $\begin{array}{l}\text { The errors of } \\
\text { the methods } \\
(24)\end{array}$ \\
\hline 0.3 & $5.47 \mathrm{E}-3$ & $5.28 \mathrm{E}-3$ & $1.57 \mathrm{E}-3$ & $9.57 \mathrm{E}-3$ & $1.91 \mathrm{E}-5$ \\
\hline 0.7 & $4.21 \mathrm{E}-3$ & $8.30 \mathrm{E}-3$ & $1.81 \mathrm{E}-3$ & $3.69 \mathrm{E}-3$ & $3.01 \mathrm{E}-5$ \\
\hline 1.1 & $4.33 \mathrm{E}-3$ & $8.36 \mathrm{E}-3$ & $1.82 \mathrm{E}-3$ & $1.36 \mathrm{E}-3$ & $3.03 \mathrm{E}-5$ \\
\hline 1.5 & $4.33 \mathrm{E}-3$ & $8.36 \mathrm{E}-3$ & $1.82 \mathrm{E}-3$ & $1.00 \mathrm{E}-2$ & $3.03 \mathrm{E}-5$ \\
\hline 2.0 & $4.33 \mathrm{E}-3$ & $8.36 \mathrm{E}-3$ & $6.70 \mathrm{E}-4$ & $1.36 \mathrm{E}-3$ & $3.03 \mathrm{E}-5$ \\
\hline
\end{tabular}

Table 6. The errors of the methods (20) with $m=-15, h=0,1$

\begin{tabular}{|c|l|l|l|l|l|}
\hline$X_{i}$ & $\begin{array}{l}\text { The errors of } \\
\text { the methods } \\
(20)\end{array}$ & $\begin{array}{l}\text { The errors of } \\
\text { the methods } \\
(21)\end{array}$ & $\begin{array}{l}\text { The errors of } \\
\text { the methods } \\
(22)\end{array}$ & $\begin{array}{l}\text { The } \\
\text { errors of } \\
\text { the } \\
\text { methods } \\
(23)\end{array}$ & $\begin{array}{l}\text { The errors of } \\
\text { the methods } \\
(24)\end{array}$ \\
\hline 0.3 & $2.15 \mathrm{E}-2$ & $1.94 \mathrm{E}-2$ & $4.67 \mathrm{E}-3$ & $4.04 \mathrm{E}-2$ & $4.22 \mathrm{E}-5$ \\
\hline 0.7 & $1.32 \mathrm{E}-2$ & $2.50 \mathrm{E}-2$ & $4.91 \mathrm{E}-3$ & $9.11 \mathrm{E}-3$ & $5.43 \mathrm{E}-5$ \\
\hline 1.1 & $1.38 \mathrm{E}-2$ & $2.50 \mathrm{E}-2$ & $4.91 \mathrm{E}-3$ & $2.03 \mathrm{E}-3$ & $5.44 \mathrm{E}-5$ \\
\hline 1.5 & $1.38 \mathrm{E}-2$ & $2.50 \mathrm{E}-2$ & $4.91 \mathrm{E}-3$ & $4.08 \mathrm{E}-2$ & $5.44 \mathrm{E}-5$ \\
\hline 2.0 & $1.38 \mathrm{E}-2$ & $2.50 \mathrm{E}-2$ & $1.09 \mathrm{E}-3$ & $2.03 \mathrm{E}-3$ & $5.44 \mathrm{E}-5$ \\
\hline
\end{tabular}

Table 7. The errors of the methods (20) with $m=-15, h=0,01$ 


\begin{tabular}{|c|l|l|l|l|l|}
\hline$x_{i}$ & $\begin{array}{l}\text { The } \\
\text { errors of } \\
\text { the } \\
\text { methods } \\
(20)\end{array}$ & $\begin{array}{l}\text { The } \\
\text { errors of } \\
\text { the } \\
\text { methods } \\
(21)\end{array}$ & $\begin{array}{l}\text { The } \\
\text { errors of } \\
\text { the } \\
\text { methods } \\
(22)\end{array}$ & $\begin{array}{l}\text { The } \\
\text { errors of } \\
\text { the } \\
\text { methods } \\
(23)\end{array}$ & $\begin{array}{l}\text { The errors } \\
\text { of the } \\
\text { methods } \\
(24)\end{array}$ \\
\hline 0.3 & $5.26 \mathrm{E}-6$ & $1.09 \mathrm{E}-5$ & $2.04 \mathrm{E}-6$ & $6.22 \mathrm{E}-6$ & $8.54 \mathrm{E}-8$ \\
\hline 0.7 & $5.33 \mathrm{E}-6$ & $1.11 \mathrm{E}-5$ & $2.07 \mathrm{E}-6$ & $5.41 \mathrm{E}-6$ & $8.67 \mathrm{E}-8$ \\
\hline 1.1 & $5.33 \mathrm{E}-6$ & $1.11 \mathrm{E}-5$ & $2.07 \mathrm{E}-6$ & $4.66 \mathrm{E}-6$ & $8.67 \mathrm{E}-8$ \\
\hline 1.5 & $5.33 \mathrm{E}-6$ & $1.11 \mathrm{E}-5$ & $2.07 \mathrm{E}-6$ & $6.29 \mathrm{E}-6$ & $8.67 \mathrm{E}-8$ \\
\hline 2.0 & $5.33 \mathrm{E}-6$ & $1.11 \mathrm{E}-5$ & $2.07 \mathrm{E}-6$ & $4.66 \mathrm{E}-6$ & $8.67 \mathrm{E}-8$ \\
\hline
\end{tabular}

\section{Conclusion}

Here was investigated the composite (generalized) quadrature formula, have demonstrated the advantages and disadvantages of these formulas. The quadrature formulas were compared and by this define the basic properties of these formulas. Here has determined the direct relation between composite quadrature formulas and the multistep methods with the constant coefficients. By illustration of advantages of the multistep methods have recommended applying them to the computation of definite integrals. And have proved that the methods proposed here are more exact than the quadrature methods. Defined disadvantages of the quadrature formulas with the maximal order of accuracy, has given the way for correction of that. By using the best properties of the hybrid, methods here have recommended application of the hybrid methods to compute definite simple integrals. And have described the advantages of the application of hybrid methods to computation of definite integrals, which have reduced to solve the initial-value problem for ODE. Some information on computing of definite integrals by using the solution of the initial-value problem for ODE can be found in the works [25]-[29].

\section{References:}

[1] Euler L., Integral calculus, volume 2, Moscow, $1957,368 \mathrm{p}$.

[2] Krylov A.N. Lectures on approximate calculations. Moscow, Gocteh-izdat, 1950.

[3] Shura-Bura M.R. Error estimates for numerical integration of ordinary differential equations, Prikl.matem. and fur., 1952, № 5, 575-588.

[4] Bahvalov N.S. Numerical methods, M. "Science"., 1975, №3, p. 510.

[5] Dahlquist G. Convergence and stability in the numerical integration of ordinary differential equations, Math.Scand, 1956, No.4, p33-53.

[6] Mehdiyeva G.Yu., Ibrahimov V.R. On the research of multi-step methods with constant coefficients. Monograph, Lambert. acad. publ., 2013
[7] Butcher J.C. A modified multistep method for the numerical integration of ordinary differential equations. J. Assoc. Comput. Math., v.12, 1965, p 124-135.

[8] Ibrahimov V.R. On a nonlinear method for numerical calculation of the Cauchy problem for ordinary differential equation. Diff. equation and applications. Proc. of II International Conference Russe. Bulgarian, 1982, pp. 310-319.

[9] Ibragimov V.R. The estimation on k-step method under weak assumptions on the solution of the given problem, Proceeding of the XI-international conference on nonlinear oscillation: august 17.23.1987, Budapest-1988.

[10] Skvortsov L.M. Explicit two-step Runge-Kutta methods, Math. modeling, 21, 2009, p. 54-65.

[11] Gelfond, A.O., Calculus of Finite Differences, 3th edition, «Nauka», Moscow, 1967, p. 311319

[12] Mehdiyeva G., Imanova M., Ibrahimov V. A way to construct an algorithm that uses hybrid methods. Applied Mathematical Sciences, HIKARI Ltd, Vol. 7, 2013, no. 98, 4875-4890.

[13] Godunov S.K., Ryaben'ky V.S. Difference schemes, Uch. pos. M .: "Science", 1977.p. 8292.

[14] Atkinson K.E. , Han W., Elementary Numerical Analysis, John Wiley and Sons, Ltd, Inc 2004, p. 205-226

[15] Quarteroni, A., Sacco, R., Saleri, F. 2007. Numerical Mathematics, Springer. 2nd edition, $680 \mathrm{p}$.

[16] R.L. Burden, J.D. Faires, Numerical analysis, Cengege Lerning, 7th edition, 2001, 196-227 p.

[17] Butcher J.C. Numerical Methods For Ordinary Differential Equations, Second edition, The university of Auckland, New Zealand, John Wiley and Sons, Ltd, v.12, 1965, p. 124-135.

[18] Gear C.S. Hybrid methods for initial value problems in ordinary differential equations. SIAM, J. Numer. Anal. v. 2, 1965, 69-86.

[19] Gupta G.K. A polynomial representation of hybrid methods for solving ordinary differential equations, Mathematics of comp., volume 33, number 148, 1979, 1251-1256.

[20] Brunner H., Marginal Stability and Stabilization in the Numerical Integration of Ordinary Differential Equations, Mathematics of Computation, Vol. 24, No. 111 (Jul., 1970), pp. 635-646

[21] Akinfewa O.A., Yao N.M., Jator S.N. Implicit Two step continuous hybrid block methods with four off steps points for solving stiff ordinary 
differential equation. WASET, 51, 2011, 425428.

[22] Hairier E., Norsett S.P., Wanner G. Solving ordinary differential equations. (Russian) M., Mir, 1990.

[23] Mehdiyeva G.Yu., Imanova M.N. Ibrahimov V.R., An application of the hybrid methods to the numerical solution of ordinary differential equations of second order, Vestnik KazNU, ser., math, mech., inf., 2012, No 4 (75).

[24] Mehdiyeva G., Imanova M., Ibrahimov V., On a way for constructing numerical methods on the joint of multistep and hybrid methods, World Academy of Sciences, Engineering And Technology, An International Journal Of Sciences, Engineering And Technology, Cemal Ardil, Paris, ISSUE 59, November 2011, p. $240-243$

[25] Mehdiyeva G., Ibrahimov V., Imanova M., On a Calculation Of Definite Integrals By Using Of The Calculation Of Indefinite Integrals, SN Applied Sciences, UK Oxford, Springer, April 2019.

[26] Mehdiyeva G., Ibrahimov V., Imanova M. On an application of the Cowell type method. News of Baku University, 2010, №2, 92-99.

[27] Imanova M.N., On some comparison of definite and indefinite integrals, Informatics and Control Problems, Transactions Of Azerbaijan National Academy Of Sciences Series Of Physical-Technical And Mathematical Sciences, Volume 39, Issue 2, No 6, p 35-47. Dajana Conte, Beatrice Paternoster, Leila Moradi, Fakhrodin Mohammadi

[28] Construction of Exponentially Fitted Explicit Peer Methods, International Journal of Circuits, Systems and Ssignal processing, pp.501-506, Volume 13, 2019

[29] Ouadie Koubaiti, Ahmed Elkhalfi, Jaouad ElMekkaoui, Nikos Mastorakis, Solving the Problem of Constraints Due to Dirichlet Boundary Conditions in the Context of the Mini Element Method, International Journal of Mechanics, pp. 12-21, Vol. 14, 2020 